INTERNATIONAL DESIGN CONFERENCE - DESIGN 2018

https://doi.org/10.21278/idc.2018.0310

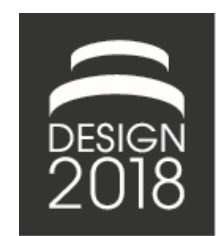

\title{
EVALUATING DESIGN HEURISTICS FOR ADDITIVE MANUFACTURING AS AN EXPLORATIVE WORKSHOP METHOD
}

\author{
A. Lindwall and P. Törlind
}

\begin{abstract}
It is suggested that the space industry is an ideal case for Additive Manufacturing (AM), with a low production volume and need for complex geometries. However, few engineers have experience of AM design. One way to support design engineers with limited experience of AM is the use of design heuristics, to enhance variety, quality and creativity of potential designs. This paper is based on literature studies and observations of creative workshops with companies from the space industry. Results showed that heuristics assisted designers and $8 / 10$ heuristics was utilised during the ideation phase.
\end{abstract}

Keywords: additive manufacturing, case study, product development, design for space, design heuristics

\section{Introduction}

The interest in additive manufacturing (AM), a collection of layer-upon-layer manufacturing processes, has lately increased due to the improved quality of metal AM processes (Wohlers and Caffrey, 2015). It is suggested that AM can bring various benefits to design (Thompson et al., 2016; Gibson, 2017), but it is also argued that there is generally insufficient understanding on how to design for AM (Campbell et al., 2012; Klahn et al., 2015; Yang and Zhao, 2015; Thompson et al., 2016; Gibson, 2017). When new products are designed through new technologies that design engineers have limited experience with, design teams need support in design to show the limitations of the new technology as well as the opportunities it offers. It is therefore argued that various heuristics need to be developed for additive manufacturing to help design engineers to explore the solution space (Gao et al., 2015). Such design heuristics are aimed to help design engineers to navigate in a possible concept space and to help them find non-obvious ideas (Daly et al., 2012). By combining different solution areas, the total solution space can become significantly increased. There is therefore a need to explore what possible design heuristics for AM there are that can be presented to design engineers. These heuristics aim to increase the possibility to create innovative solutions and assist designers in adopting an understanding of AM in design. The interest in designing products with complex geometries for metal AM has increased within aerospace industries (Gibson, 2017). Products for space applications such as satellites and rockets have a great potential to adopt AM technologies, since parts with complex geometries that are produced in low volumes are ideal for AM (Wohlers and Caffrey, 2015). Therefore, the study presented in this paper is performed in a space industry context, with design engineers that have high experience in product development and limited experience in AM. The study initially evaluates design heuristics for AM that can be of assistance for design engineers, through traditional DFM/A guidelines and current literature in AM design to limit the number of design heuristics. The study aims to (1) identify design heuristics on a higher level, which can then be presented to design engineers in the space industry with 
limited knowledge of AM, and (2) explore the usage of such heuristics in a creative workshop, with space-related products, that includes design engineers with limited previous experience in design for AM.

\subsection{Research setting}

The research is carried out as a demonstrator project between two Swedish universities (Luleå University of Technology and Chalmers) and three space-related companies (case companies). One of the goals is to challenge and identify alternative design solutions that utilise the potential AM has for space components. The demonstrator project uses a facilitated workshop approach that utilises the 'Tiger Team' approach. True to its name, the Tiger Team (Ashley, 1992) approach is a powerful way of composing a special, multidisciplinary task force to rapidly solve a problem. The tiger teams aim to reach true collaboration, where diversity and competences of the whole team can be utilised. This leads to the possibility of team members to collaborate by using fragments of ideas from others as well as gestures and drawings to create new ideas rather than merely exchanging information or opinions and dividing work (Törlind et al., 2005). By bringing together external experts and innovators, existing working methods and obstacles, e.g., "we've always done it like this", will be questioned. In the workshop series (Figure 1) with academia and participating companies, the maturity of the concept is being developed in five steps planned to last for 18 months, from autumn 2017 until the end of 2018. The first two workshops focus on developing a conceptual design of each case product, while the final three workshops focus on verifying and qualifying the product through extensive testing of the printed designs. Design results from the first workshops highly affect work made in the final workshops, where the combined workshops and internal work in-between the workshops can determine workshop designs.

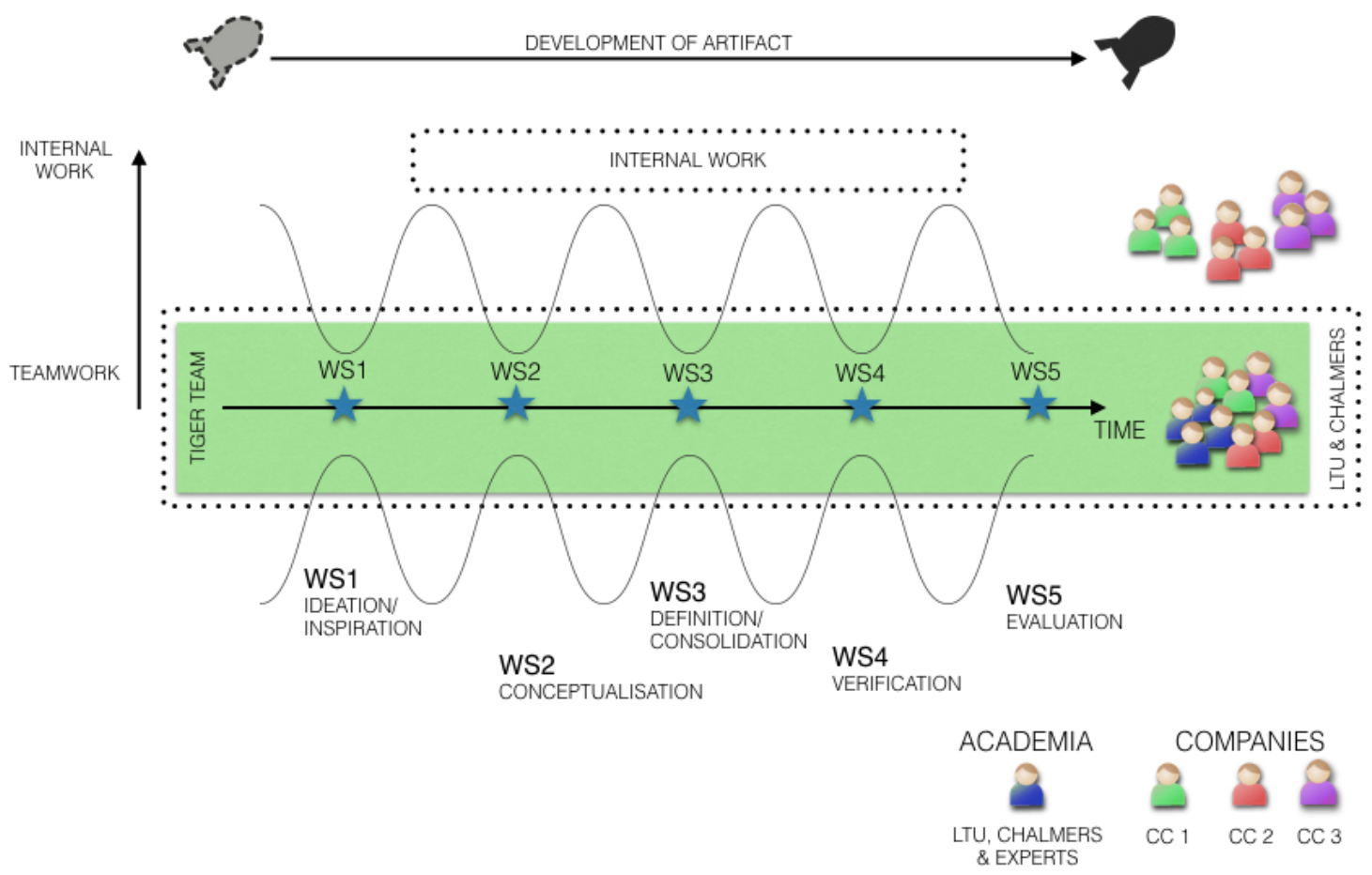

Figure 1. Illustration of the workshop series

The Tiger team consists of company experts that have an extensive experience in design for space; the researchers have a more general engineering knowledge as well as an expert knowledge in design processes. In the workshops, companies are expected to work intensively with each other's problems 
with the support of academic experts. After each workshop, challenges and unknowns are identified that companies and the participating experts need to explore on their own (with the support of the ordinary design teams) before the next workshop.

\section{Additive manufacturing in the space industry}

While the usage of AM has increased in several industries throughout the world (Wohlers and Caffrey, 2015), it has also been shown that aerospace industries (space included) have an increased interest in AM with an aim to create a higher product value (Gibson, 2017; Steenhuis and Pretorius, 2017). Products for space applications, such as satellites and rockets, are ideal for AM, since parts are produced in low volumes and are often difficult to manufacture with traditional processes (Wohlers and Caffrey, 2015). The products often have high safety requirements, where many of the system architectures have been established in the past and have barely been changed since (Fortescue et al., 2011). While introducing AM as a possible manufacturing method within the space industry, new values can be created through, for example, new geometries or lower weights. This seems to bring a hope to increase the design space and providing innovative possibilities for space products (Lindwall et al., 2017). Various examples of AM printed artefacts for space applications can be shown, such as a rocket engine for nanosatellites that have been printed as a whole through the powder bed fusion process (LLNL, 2017). The first prototype was printed in eight days with a total cost of $\$ 10,000$, which makes it more cost effective than the traditional manufacturing processes. A study on the development process for antenna feed arrays has been made with the usage of certain AM design rules (Gill et al., 2017). The study also showed a comparison of the AM approach to the traditional manufacturing approach, which resulted in fewer parts, a lighter weight and a decreased manufacturing time by at least 20 hours. Such examples show that the specific interest of AM in the space industry introduces the possibility of adopting many of the benefits provided by AM. There are more examples illustrating the same effect on $\mathrm{AM}$ in design projects within the space industry. Lockheed Martin has printed a spherical titanium tank used for one of their satellite buses, with a decreased time span from 18 months to less than 6 months (Caleb, 2017). At the same time, Aerojet Rocketdyne has successfully tested a full-scale thrust chamber with a part count reduced by more than 90 percent (Caleb, 2017). It is hard to argue against the possibilities and benefits that AM can provide product design projects in the space industry. The special setting with high safety requirements and various stakeholders in design makes it important to explore $\mathrm{AM}$ in such a complex and special context.

\section{Creativity and design heuristics}

Often engineering design is focused on enhancing the performance of a product by giving them the ability to handle higher stresses (higher stress, less material), making them lighter (same stress, less material) or allowing for other design perspectives. These perspectives often include Design for X methods, such as design for manufacturing, where a reduction of complexity can reduce cost and at the same time bring improved performance (Ulrich and Eppinger, 2012). AM is considered to offer various benefits to design, such as a more extensive design space (Thompson et al., 2016; Gibson, 2017), which can increase the possibilities of being creative. However, it is argued that one of the ultimate limitations of AM in design is the imagination of the designer (Campbell et al., 2012). It has been shown that specified design heuristics support designers to explore the possible design space, where cognitive heuristics from the memories of designers are applied to the solution space (Yilmaz and Seifert, 2011). It is proposed that design heuristics can guide design engineers through the possible design space through several characteristics that can create new designs. Significant changes in the domain are often considered to be the most difficult to work with, due to its ambiguity, and it is argued that clearly defined goals and boundaries are of great importance to enhancing creativity (Csikszentmihalyi, 1996). Such boundaries are today considered to have been changed through AM, due to the new and wider possible solution space. Therefore, designers with expert knowledge in product design, but limited knowledge of AM in design, need support through design heuristics specifically for AM (Gao et al., 2015). A person with high expertise in an area can more easily explore and solve problems through creativity (Amabile, 1998), and designers with expert knowledge in design are argued to utilise heuristics more fully than novices (Yilmaz and Seifert, 2011). Hence, design strategies for AM, such 
as design heuristics, have recently gained an increased interest and are considered helpful for design engineers to fully utilise the new design space (Gao et al., 2015; Blösch-Paidosh and Shea, 2017). In this paper, design heuristics are defined as a cognitive help to point designers towards the exploration of design variations (Daly et al., 2012). Heuristics are aimed to create endless variations of ideas, through new combinations as well as developments in new and unknown directions. Design heuristics are argued to enhance variety, quality and creativity for the potential designs of the solution space (Yilma and Seifert, 2011) and could increase the number of possibilities for innovative solutions (Daly et al., 2012).

\section{Identifying design heuristics for additive manufacturing}

To identify design heuristics that can be of interest in the space industry, the work was initiated with literature investigations on design strategies for AM. The study included the work conducted by BlöschPaidosh and Shea (2017) when it was published, that had derived 29 design heuristics for AM from a pool of over $200 \mathrm{AM}$ artefacts. It was judged that the number of design heuristics presented to design engineers needed to be limited, to make sure that it was possible to go through all heuristics during a one-day workshop. The heuristics were therefore first categorised into areas that are expected to fulfil the same or similar action. Three main design areas were identified with the assistance of a list of traditional DFM/A guidelines that was collected through the literature (Figure 2).

\section{DFM/A GUIDELINES}

- Reduce part count

- Reduce assembly time

- Reduce manual handling time

- Facilitate automatic handling

- Process controllability

- Design for easy insertion

- Avoid tight tolerances

- Standardise design features
- Minimise systemic complexity

- Reduce manufacturing time

- Design a mistake-proof assembly

- Simplify the design

- Minimise assembly directions

- Minimise secondary \& finishing operations

- Design multifunctional parts

Figure 2. DFM/A guidelines adapted from Boothroyd (1994), Pahl and Beitz (1996), Poli (2001), and Ulrich and Eppinger (2012)

Each design area and its design heuristics was therefore developed through finding literature that discussed similar aspects in design of interest or importance when designing for AM. These were put into a table to provide an overview of what areas could be compiled and had similar aspects (Table 1). For example, DfM/A guidelines that included reducing part count, simplifying design and designing multifunctional parts was related to design heuristics presented in the literature and categorised under the design area of part consolidation. Blösch-Paidosh and Shea (2017) had heuristics such as 'consolidate parts for better functional performance' and 'embed functional component' that was also categorised under consolidation. The three design areas for AM were also studied through literature (e.g. Gao et al., 2015; Gibson et al., 2015; Thompson et al., 2016) to gain an understanding of what perspectives could be taken into account in such areas and to identify the design heuristics.

Part consolidation is aimed at enabling the production of a part that with traditional manufacturing methods would require an assembly of several parts (Thompson et al., 2016). Some of these parts can be combined with each other with AM through integrated designs (Gao et al., 2015). Consolidating parts and limiting assemblies can assist design by keeping the product compact and avoiding leakage. Another way to consolidate is to manage internal designs through the inner part (Gibson et al., 2015). In many cases, it also brings greater value to the end product with specific inner features such as cooling channels. 
For example, a method has been developed to assist the design of optimal internal channels and ultimately to address pressure losses and heat transfers (Pietropaoli et al., 2017).

\section{Table 1. Overview of design heuristics and their characteristics}

\begin{tabular}{|c|c|c|}
\hline Design heuristic & DFM/A guideline & AM literature discussions \\
\hline Integrated design & $\begin{array}{l}\text { reduce part count; simplify design; } \\
\text { design multi-functional parts; reduce } \\
\text { assembly time }\end{array}$ & $\begin{array}{l}\text { elimination of assembly features } \\
\text { including new possible design features; } \\
\text { produce less parts; increase functional } \\
\text { performance with integrated designs; } \\
\text { remove material and design } \\
\text { lightweight parts }\end{array}$ \\
\hline Internal design & $\begin{array}{l}\text { reduce part count; simplify design; } \\
\text { design multi-functional parts; minimise } \\
\text { systemic complexity; reduce assembly } \\
\text { time }\end{array}$ & $\begin{array}{l}\text { involve complex internal structures; } \\
\text { customisation of internal geometry; } \\
\text { increase functional performance with } \\
\text { internal designs; design multiple } \\
\text { functions }\end{array}$ \\
\hline Embedded design & $\begin{array}{l}\text { reduce part count; simplify design; } \\
\text { design multi-functional parts; reduce } \\
\text { assembly time }\end{array}$ & $\begin{array}{l}\text { embed functional components; design } \\
\text { multiple functions; reduce number of } \\
\text { parts to assemble; include external } \\
\text { functions embedded in parts; reduce } \\
\text { the need for fasteners }\end{array}$ \\
\hline $\begin{array}{l}\text { Interlocking } \\
\text { features }\end{array}$ & $\begin{array}{l}\text { reduce assembly time; minimise assembly } \\
\text { directions; design a mistake-proof } \\
\text { assembly; reduce manual handling time }\end{array}$ & $\begin{array}{l}\text { simplify assembly and disassembly; } \\
\text { limited build chamber can require } \\
\text { division of parts; strengthen part } \\
\text { through its own geometry }\end{array}$ \\
\hline Embedded joints & $\begin{array}{l}\text { reduce assembly time; minimise assembly } \\
\text { directions; design a mistake-proof } \\
\text { assembly; reduce manual handling time }\end{array}$ & $\begin{array}{l}\text { use enclosed and functional parts; have } \\
\text { moving parts in one artefact; reduce } \\
\text { assembly with print-ready assembly }\end{array}$ \\
\hline Form synthesis & $\begin{array}{l}\text { minimise systemic complexity; reduce part } \\
\text { count; minimise systemic complexity; } \\
\text { reduce manufacturing time; simplify the } \\
\text { design; design multifunctional parts }\end{array}$ & $\begin{array}{l}\text { optimise design shapes for a certain } \\
\text { purpose; design new organic shapes; } \\
\text { customise shapes; design multi- } \\
\text { functional parts }\end{array}$ \\
\hline $\begin{array}{l}\text { Topology } \\
\text { optimisation }\end{array}$ & $\begin{array}{l}\text { minimise systemic complexity; reduce part } \\
\text { count; minimise systemic complexity; } \\
\text { reduce manufacturing time; simplify the } \\
\text { design; design multifunctional parts }\end{array}$ & $\begin{array}{l}\text { optimise geometry through } \\
\text { mathematical software calculations; } \\
\text { design completely based on given } \\
\text { loads and boundaries; design multi- } \\
\text { functional parts; reduce weight through } \\
\text { optimised geometries }\end{array}$ \\
\hline $\begin{array}{l}\text { Anisotropic } \\
\text { structures }\end{array}$ & $\begin{array}{l}\text { design multifunctional parts; minimise } \\
\text { systemic complexity, Process } \\
\text { controllability }\end{array}$ & $\begin{array}{l}\text { optimise material properties; design } \\
\text { materials varying along a part; produce } \\
\text { functional materials; embed functional } \\
\text { material; process materials at certain } \\
\text { points or layers }\end{array}$ \\
\hline $\begin{array}{l}\text { Multiscale } \\
\text { structures }\end{array}$ & $\begin{array}{l}\text { minimise secondary \& finishing } \\
\text { operations; design multifunctional parts; } \\
\text { minimise systemic complexity, Process } \\
\text { controllability }\end{array}$ & $\begin{array}{l}\text { create a multi-functional part; replace } \\
\text { internal structures with lattice } \\
\text { structures; ensure strength and } \\
\text { flexibility through structures; reduce } \\
\text { weight with less material; distribute } \\
\text { material to get desired properties }\end{array}$ \\
\hline Multi-materials & $\begin{array}{l}\text { design multifunctional parts; minimise } \\
\text { systemic complexity, process } \\
\text { controllability }\end{array}$ & $\begin{array}{l}\text { use multi-materials to increase material } \\
\text { properties and vary materials along a } \\
\text { part; embed functional material; } \\
\text { combine materials in a part }\end{array}$ \\
\hline
\end{tabular}


Embedding external components such as electronics in a mechanical part can bring many values to end products. Embedded designs can also reduce the need for fasteners by embedding bolts or nuts into the part (Gibson et al., 2015). Another design area identified for AM was named connection elements, where heuristics such as 'use enclosed, functional parts' and 'absorb energy with small interconnected parts' (Blösch-Paidosh and Shea, 2017) were categorised together. Since the volume of AM builds is limited, large parts might still need to be divided into several parts (Gibson et al., 2015). One way to address this is to design connecting components that can be assembled and disassembled on a regular basis (Song et al., 2015) through interlocking features. However, it could also be important to acknowledge that there might be a value in interlocking features even if the part fits in the build chamber. There can also be a value in including moving parts in a component, such as joints. AM can build these, fully assembled, in one build (Gibson et al., 2015).

The third design area identified for AM includes a variety of perspectives and has been called structure design. This one includes heuristics such as 'hollow out artefact to reduce weight' and 'embed functional material' (Blösch-Paidosh and Shea, 2017) in its categorisation. One structural perspective that can assist designers is the usage of form synthesis design tools. Such tools are designed to synthesise various design solutions in organic viewpoints and one example of such a program is 'project dreamcatcher' (Autodesk, 2017). This approach helps designers to explore alternative designs and compare them to each other. Another perspective that also has emerged for assistance in design is computational topology optimisations (Leary et al., 2014). The topological optimisation method uses the mathematical approach within a specified design space, given load and boundary conditions (Gardan, 2016). In some products, there is a need for specific properties on one part of the article and other properties in another part, which can be feasible with AM through anisotropic structures. The material complexity available with AM makes it possible to process the material at one point or layer at a time, enabling complex material compositions (Yang and Zhao, 2015). Multiscale complexities can also bring values to a component through ensuring strength, flexibility and lighter weight. The structural design can be composed in such way that the part is shape-optimised (Gao et al., 2015), which creates the possibility of creating the desired properties and functions of a product (Gardan, 2016). A final perspective within the structure design is the possibility of including multi-material designs, where the article can have several materials within one article (Gibson et al., 2015). The various perspectives within the three design areas are distinguished as the design heuristics used in the empirical study included in this paper (Figure 3).

\begin{tabular}{|c|c|c|c|c|c|c|c|c|c|}
\hline \multicolumn{3}{|c|}{ Part consolidation } & \multicolumn{2}{|c|}{$\begin{array}{l}\text { Connection } \\
\text { elements }\end{array}$} & \multicolumn{5}{|c|}{ Structure design } \\
\hline $\begin{array}{l}\text { Integrated } \\
\text { design }\end{array}$ & $\begin{array}{l}\text { Internal } \\
\text { design }\end{array}$ & $\begin{array}{l}\text { Embedded } \\
\text { design }\end{array}$ & $\begin{array}{l}\text { Interlocking } \\
\text { features }\end{array}$ & $\begin{array}{c}\text { Embedded } \\
\text { joints }\end{array}$ & $\begin{array}{l}\text { Form } \\
\text { synthesis }\end{array}$ & $\begin{array}{l}\text { Topology } \\
\text { optimisation }\end{array}$ & $\begin{array}{l}\text { Anisotropic } \\
\text { structures }\end{array}$ & $\begin{array}{l}\text { Multiscale } \\
\text { structures }\end{array}$ & $\begin{array}{l}\text { Multi- } \\
\text { materials }\end{array}$ \\
\hline
\end{tabular}

Figure 3. Illustration of the design areas and their design heuristics

\section{A creative workshop with space-related cases}

In September 2017, the design heuristics were evaluated for nine participants in a creative workshop managed by the authors. The participants were engineers working with product development for space applications who were employed at one of the three case companies (Table 2). All participants of the workshop had 12-30 years of experience in product development. Some of them had worked with classical engineering design such as $\mathrm{CAD}$ and mechanical engineering, but others worked in areas such as simulation and material engineering. Also, approximately $45 \%$ of the participants reported having, to various degrees, experience in AM before the workshop. Each case company had been assigned to bring an example of a product intended to be redesigned for AM, which in this paper will be referred to as case products. 
Table 2. Presentation of case companies and participants of the workshop

\begin{tabular}{clll} 
Company & \multicolumn{1}{c}{ Company description } & Participants & \multicolumn{1}{c}{ Roles of participants } \\
\hline$A$ & $\begin{array}{l}\text { The company is developing complex } \\
\text { and high-performance components for } \\
\text { the aerospace sector. }\end{array}$ & $\begin{array}{l}\text { Design leaders and design } \\
\text { engineers }\end{array}$ \\
$B \quad \begin{array}{l}\text { The company operates in Low Earth } \\
\text { Orbit constellation programs. } \\
\text { Responsibility includes the whole } \\
\text { chain, from R\&D to sales for several } \\
\text { product areas. }\end{array}$ & $\begin{array}{l}\text { Design engineer and simulation } \\
\text { expert }\end{array}$ \\
$C \quad \begin{array}{l}\text { A company that focuses on product } \\
\text { development for space systems and } \\
\text { satellites, and is involved in several } \\
\text { highly critical projects. }\end{array}$ & 3 & $\begin{array}{l}\text { System engineer, project manager } \\
\text { and chief technology officer }\end{array}$ \\
\end{tabular}

This first workshop was performed during one and a half days at case company $\mathrm{C}$ and was initiated with a presentation of the company and a tour of their facilities. For a simplified presentation of the workshop schedule, see Figure 4.

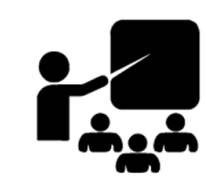

Design Heuristics

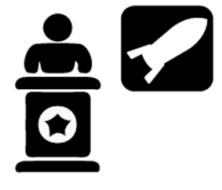

Case presentations

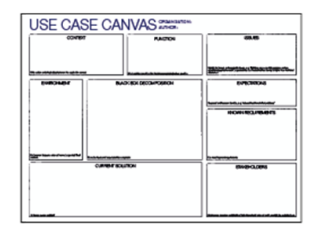

Use Case Canvas

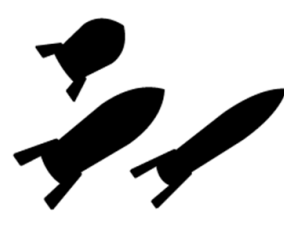

Ideation $\times 3$

Figure 4. The workshop process for workshop 1

The participants filled in a survey on their own perceived experience with the identified design heuristics, before any one of them was presented or discussed. Such information was obtained to see the pre-knowledge of the participants in relation to the discussions of the design heuristics. The authors presented the design heuristics together with inspirational examples of AM artefacts from the space sector (e.g., satellite parts, rocket propulsion systems). Discussions were held during the presentation regarding some of the heuristics, such as the possibility of printing embedded joints directly in one build. An example of embedded joints for space applications that was brought up was the possibility of having a structure that unfolds itself due to a response to temperature changes. Participants were interested in this example, since some functions are not needed until the product is already launched into space.

After the presentation, participants were encouraged to describe the context, expectations, known requirements and black box decomposition to the other participants. The second day consisted of the ideation phase, where each case product was the focus for 45 minutes, with the intention of each to include the design heuristics. Each case had a general discussion with the entire group and briefer ideation activities in smaller groups (approximately three persons in each group). The workshop was finished with a conclusion of the two days and an evaluation of the workshop. Discussions from each day were documented at the workshop by one of the authors, while two other colleagues made notes and took pictures. Participants made sketches and drawings of their ideas during the workshop, which were also included in the documentation. A final document was designed with the ongoing documentation, notes, pictures, sketches and drawings included. The discussions from the ideation phase have been analysed through a form of content analysis, where written data were sorted into categories to arrive at an understanding of the information conveyed by the participants (Krippendorff, 2004). 
These categories were pre-decided in a coding matrix (Flick, 2014), with the case products in one axis and the design heuristics in the other.

\section{Empirical results}

This section presents the empirical results provided by the conducted workshop. The implications are organised according to each case product, with a description of ideas given in the ideation phase. While the documentation of the discussions in the ideation phase was analysed, the ideas were categorised into a matrix (Table 3) for a general overview. Overall, the discussions in the workshop showed that the design engineers had their own perceptions on some of the design heuristics that were presented. Most of the general discussions, both during the presentation of design heuristics and the presentations of each case product, was focused on topological optimisation and anisotropic structures. Even though the participants did not necessarily use the term 'anisotropic structures', they knew the concept of developing the material properties needed for a specific point in a part.

Ideation for Case Product A illustrated various opportunities for redesigning the product for AM, where the discussions initially covered questions on where the boundaries were. Design engineers from case company A initiated a preparation for AM, but the original design required a greater support structure than they had anticipated. Therefore, the participants from the case company specifically asked the workshop participants to contribute insights on new geometries and to avoid traditional manufacturing thinking. The workshop activities resulted in ideas covering designs where all parts would be integrated into one article, including internal structures, rethinking internal and external shapes, and using graded or porous material, ceramic surfaces and including lattice structures. There were similar discussions regarding Case Product B, where the participants immediately saw the potential to integrate parts and support in the design. The desire was that AM would create the possibility to design as needed, instead of being limited by traditional manufacturing constraints. The ideation phase resulted in such ideas as having simple and cheap supports entirely for the launch, as the support is unnecessary while in space and can, therefore, be discarded. Some design features on the original design could also be eliminated, according to other discussions. Participants from case company $\mathrm{C}$ were hopeful that AM could result in the design of Case Product $\mathbf{C}$ having fewer interfaces and weight reductions. Other ideas that emerged through the discussions were to include interlocking features through locking rotations or keyhole slots. However, a recurring obstacle was the pre-established boundaries of the product, which were given by customers.

Table 3. Matrix analysis

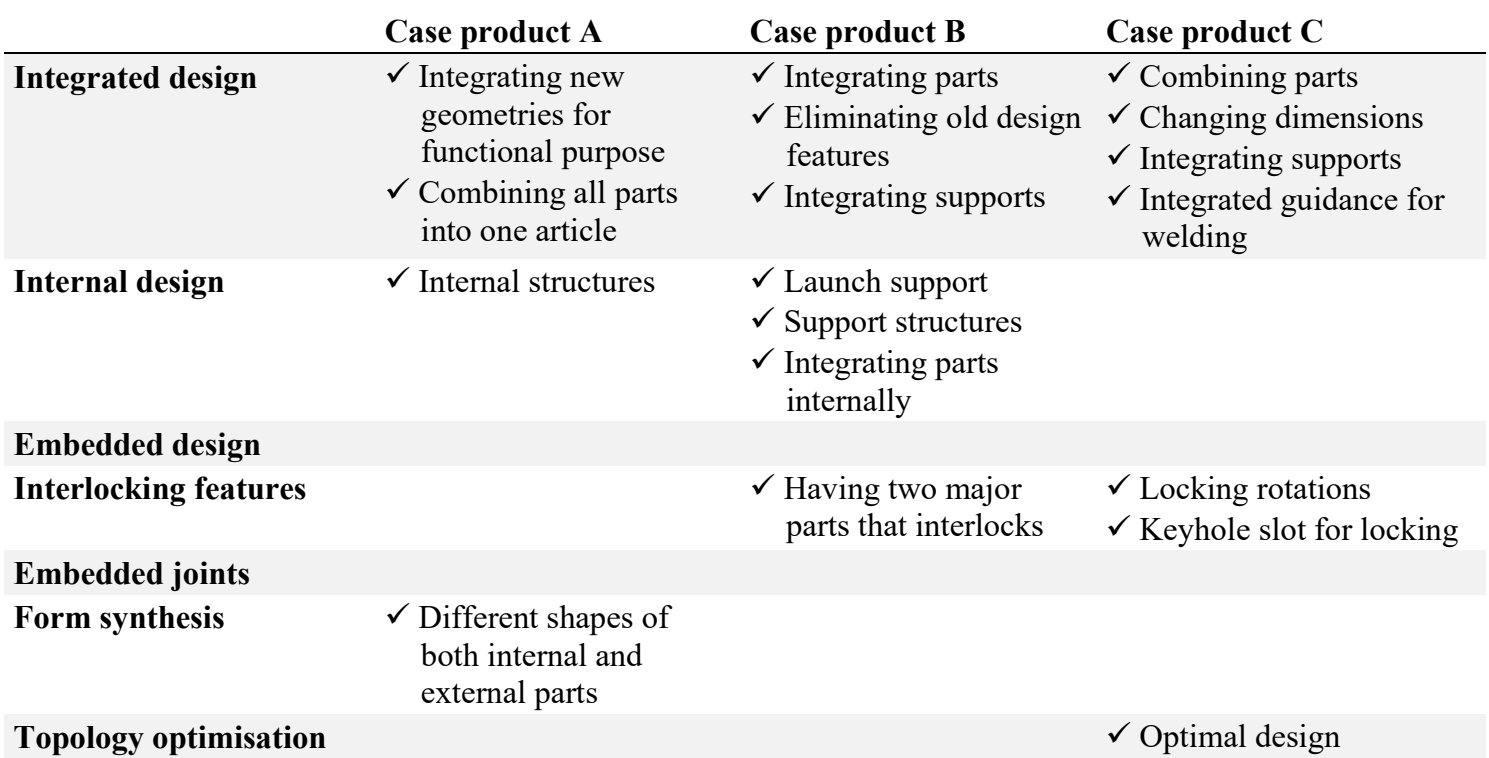




\begin{tabular}{|c|c|c|c|}
\hline & & & $\begin{array}{l}\checkmark \text { Optimisation of material } \\
\quad \text { use }\end{array}$ \\
\hline Anisotropic structures & $\begin{array}{l}\checkmark \text { Using graded material } \\
\text { due to the temperature } \\
\text { difference }\end{array}$ & $\begin{array}{l}\checkmark \text { Functional stiffness } \\
\text { supports }\end{array}$ & $\checkmark$ Material optimisation \\
\hline Multiscale structures & $\begin{array}{l}\checkmark \text { Including lattice } \\
\text { structures } \\
\checkmark \text { Unsymmetrical } \\
\quad \text { geometry }\end{array}$ & $\begin{array}{l}\checkmark \text { Geometry lightened by } \\
\text { holes or nets } \\
\checkmark \text { Net structures }\end{array}$ & \\
\hline Multi-materials & $\begin{array}{l}\checkmark \text { Using porous material } \\
\text { internally } \\
\checkmark \text { Using a ceramic } \\
\text { surface }\end{array}$ & $\begin{array}{l}\checkmark \text { Coating that } \\
\text { withstands } \\
\text { temperature changes }\end{array}$ & $\checkmark$ Surface treatment/coating \\
\hline
\end{tabular}

By studying the generated matrix (Table 3), some connections can be drawn. All three case products have to some extent included integrated design, anisotropic structures and multi-materials in the ideation activities. However, the only design heuristic that was not included in any of the ideation activities was embedded joints, even though a discussion regarding its possibilities was brought up during the presentation of the heuristics. The survey that was filled in by the participants showed an average knowledge level (Table 4) and showed that topology optimisation and integrated design were the most well-known design heuristics before the workshop. However, even though topology optimisation was well-known, it was sparingly used in the case products during the creative activities of the workshop.

Table 4. Average knowledge of heuristics in relation to use in the cases

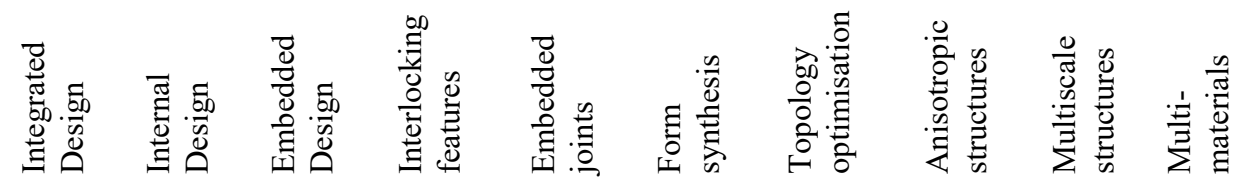

\begin{tabular}{|c|c|c|c|c|c|c|c|c|c|c|}
\hline $\begin{array}{l}\text { Average } \\
\text { Knowledge } \\
(\max 7, \min 1)\end{array}$ & 4.7 & 4 & 3.1 & 3.3 & 2 & 2 & 4.2 & 2.7 & 2.8 & 2.5 \\
\hline $\begin{array}{l}\text { Used in } \\
\text { number of } \\
\text { cases }\end{array}$ & 3 & 2 & 0 & 2 & 0 & 1 & 1 & 3 & 2 & 3 \\
\hline
\end{tabular}

\section{Concluding discussion}

This study has identified ten design heuristics for AM on a higher level that can assist design engineers with high experience in product development, but limited experience in design for AM. These heuristics have been explored in a creative workshop together with design engineers from the space industry, with three case products in focus. The findings from this study suggest that many of the heuristics for AM can be useful for products designed for space applications. Therefore, we suggest that design heuristics for AM open up possibilities for engineers with limited experience in AM to clearly explore the new design space. Some of the heuristics were, however, not used to the same extent as others, such as embedded design, embedded joints, form synthesis and topology optimisation. Some heuristics where participants perceived a lower knowledge level, such as embedded joints or form synthesis, were not used to the same extent as some of the other heuristics. However, embedded joints have been suggested as having been excluded in the creative activities since the case products used in the creative workshop were all mainly static with either no or few moving parts. We also suggest that the exclusion of embedding external components could be for a similar reason: that is, that the case products were mainly 
static and did not have such functions. However, embedding components could still be of interest if the case companies would like to attach sensors for evaluating their product in use. The other two heuristics, topology optimisation and form synthesis, which were sparingly discussed in the creative activities, could have been excluded due to the possibility of using them in a later stage, since today they are included in many of the available CAD programs. They are therefore more suitable to use in detail design phases, when virtual models are more thoroughly designed.

The heuristics that were discussed primarily were either in the design areas of part consolidation or structure design. Table 4 suggests that design heuristics in the area of structure design that were perceived to be less known before the workshops, such as anisotropic structures, multiscale structures and multi-materials, were a major topic of the creative discussions. The focus on structure design is suggested to be of importance due to the identified risk of insufficient qualification or verification approaches for AM in an industry with such high requirements and risks (Lindwall et al., 2017; Dordlofva, 2018). Products launched into space can have high variations of temperatures, with the heat from the rocket engine being one issue and the coldness of space another. This put high demands on what materials need to withstand and, together with other aspects such as radiation hazards and vacuum, the design of product properties can be crucial. We suggest that the design heuristics for AM presented in this paper can assist designers in adopting an understanding of how to explore the design space through creative activities in design for AM. Since a majority of the heuristics (all but two) was discussed at some point during the creative activities of the workshop, it is suggested that engineers start to reflect on and use the presented heuristics in early encounters with the new solution space. Therefore, this study indicates that engineers find support in using design heuristics for AM when exploring new possible design spaces with this new manufacturing technology.

The study of design heuristics was based on the literature and was adapted to the space industry. Each heuristic was researched through the literature and presented during the workshop to enhance the possibilities that participants would arrive at a general idea and be similarly exposed to each heuristic. Presenting the design heuristics in relation to the current literature was done to increase the shared knowledge level of participants in the workshop and to raise the level of the creative discussions and related activities. However, there was no testing on whether the participants had the same or a similar understanding and knowledge of the heuristics. The space industry is today exploring the possibilities of including AM benefits in their designs, and there are many examples of space-related companies with printed and tested designs. However, since there are no known reports of AM printed parts that have been deemed 'critical', e.g. with loads that make the part necessary for the primary purpose of the product, many are still hesitant towards adopting AM for all components in the space industry (Dordlofva, 2018). Such discussion relates back to the insecurity of not having sufficient approaches to qualify or verify products and their durability.

Overall, this study suggests that design heuristics for AM can be useful in the creative phases of product development toward expanding design. Not all heuristics are useful for every single product, but the heuristics can give a hint on what designs can be used and how they can be combined.

\section{Future work}

The authors of this paper will continue following the development of the case products for four more workshops with various focuses, such as conceptualisation, where the case companies will have continued working on their designs between the meetings. Further discussions and conclusions can therefore be presented later on in the project, with respect to the full utilisation of the design heuristics in the concept development phase of product design for space applications.

\section{Acknowledgements}

We acknowledge the LTU Graduate School of Space Technology and the EU project RIT (Space for Innovation and Growth) for financial support. 


\section{References}

Amabile, T.M. (1998), "How to kill creativity", Harvard Business Review, Vol. 76 No. 5, pp. 77-87.

Ashley, S. (1992), "DARPA Initiative in Concurrent Engineering. Defense Advanced Research Projects Agency", Mechanical Engineering-CIME, Vol. April.

Autodesk (2017), Project Dreamcatcher. [online] Autodesk. Available at: https://autodeskresearch.com/projects/dreamcatcher (accessed 10.11.2017)

Boothroyd, G. (1994), "Product design for manufacture and assembly", Computer-Aided Design, Vol. 26 No. 7 , pp. 505-520. https://doi.org/10.1016/0010-4485(94)90082-5

Blösch-Paidosh, A. and Shea, K. (2017), "Design Heuristics for Additive Manufacturing”, Proceedings ICED 17, the 21st International Conference on Engineering Design, Vol. 5, Design for X, Vancouver, Canada, August 21-25, 2017, The Design Society, Glasgow, pp. 91-100.

Caleb, H. (2017), SpaceX demonstrates rocket reusability with SES-10 launch and booster landing. [online] SpaceNews. Available at: http://spacenews.com/spacex-demonstrates-rocket-reusability-with-ses-10-launchand-booster-landing/ (accessed 08.11.2017).

Campbell, I., Bourell, D. and Gibson, I. (2012), “Additive manufacturing: rapid prototyping comes of age", Rapid Prototyping Journal, Vol. 18 No. 4, pp. 255-258.

Csikszentmihalyi, M. (1996), Creativity - Flow and the Psychology of Discovery and Invention, Harpercollins Publishers, New York.

Daly, S.R., Yilmaz, S., Christian, J.L., Seifert, C.M. and Gonzalez, R. (2012), "Design heuristics in engineering concept generation”, Journal of Engineering Education, Vol. 101 No. 4, pp. 601-629.

Dordlofva, C. (2018), Towards qualification for additive manufacturing in space industry, Licentiate Thesis, Luleå University of Technology. (In press)

Flick, U. (2014), An introduction to qualitative research, 5th ed., SAGE publications, London.

Fortescue, P., Swinerd, G. and Stark, J. (2011), Spacecraft Systems Engineering, 4th ed., John Wiley \& Sons, Chichester.

Gao, W., Zhang, Y., Ramanjuan, D., Ramani, K., Chen, Y. et al. (2015). “The status, challenges, and future of additive manufacturing in engineering”, Computer-Aided Design. Vol. 69 No. 1, pp. 65-89. https://doi.org/10.1016/j.cad.2015.04.001

Gardan, J. (2016), “Additive manufacturing technologies: state of the art and trends", International Journal of Production Research, Vol. 54 No. 10, pp. 3118-3132.

Gibson, I., Rosen, D.W. and Stucker, B. (2015), Additive Manufacturing Technologies: Rapid prototyping to Direct Digital Manufacturing, 2nd ed., Springer, New York.

Gibson, I. (2017), "The changing face of additive manufacturing”, Journal of Manufacturing Technology Management, Vol. 28 No. 1, pp. 10-17.

Gill, S.S., Arora, H. and Judesh, V.S. (2017), “On the development of Antenna feed array for space applications by additive manufacturing technique", Additive Manufacturing, Vol. 17, pp. 39-46.

Klahn, C., Leutenecker, B. and Meboldt, M. (2015), "Design Strategies for the Process of Additive Manufacturing", Procedia CIRP, Vol. 36, pp. 230-235.

Krippendorff, K. (2004), Content Analysis: An Introduction to Its Methodology, 2nd ed., SAGE publications: Thousand Oaks, London, New Delhi.

Leary, M., Merli, L., Torti, F., Mazur, M. and Brandt, M. (2014), ”Optimal topology for additive manufacture: A method for enabling additive manufacture of support-free optimal structures", Materials and Design, Vol. 63, pp. 678-690.

Lindwall, A., Dordlofva, C. and Öhrwall Rönnbäck, A. (2017), “Additive Manufacturing and the Product Development Process: Insights from the Space Industry", ICED 17, the 21st International Conference on Engineering Design, Vancouver, Canada, August 21-25, 2017, The Design Society, Glasgow.

LLNL (2017), Printed metal parts meet critical national needs. [online] Lawrence Livermore National Laboratory. Available at: https://manufacturing.llnl.gov/additive-manufacturing/metal-additive-manufacturing (accessed 14.08.2017).

Pahl, G. and Beitz, W. (1996), Engineering Design, 2nd ed., Springer-Verlag, London. 
Pietropaoli, M., Ahlfield, R., Mintomoli, F., Ciani, A. and D'ercole, M. (2017), "Design for Additive Manufacturing: Internal Channel Optimization”, Journal of Engineering for Gas Turbines and Power, Vol. 139 No. 10. https://doi.org/10.1115/1.4036358

Poli, C. (2001), Design for Manufacturing: A Structured Approach, Butterworth-Heinemann, Boston.

Song, P., Fu, Z., Liu, L. and Fu, C.-W. (2015), "Printing 3D objects with interlocking parts", Computer Aided Geometric Design, Vol. 35-36, pp. 137-148. https://doi.org/10.1016/j.cagd.2015.03.020

Steenhuis, H-J. and Pretorious, L. (2017), "The additive manufacturing innovation: a range of implications", Journal of Manufacturing Technology Management, Vol. 28 No. 1, pp. 122-143.

Thompson, M.K., Moroni, G., Vaneker, T., Fadel, G., Campbell, R.I. et al. (2016), "Design for Additive Manufacturing: Trends, opportunities, considerations, and constraints", CIRP Annals - Manufacturing Technology, Vol. 65, pp. 737-760.

Törlind, P., Larsson, A., Löfstrand, M. and Karlsson, L. (2005), “Towards true collaboration in global design teams?", ICED 05, the 15th International Conference on Engineering Design, Melbourne, Australia, August 15-18, 2005, The Design Society, Glasgow.

Ulrich, K.T. and Eppinger, S.D. (2012), Product Design and Development, 5th ed., McGraw-Hill, New York.

Wohlers, T. and Caffrey, T. (2015), Wohlers report 2015: 3D printing and additive manufacturing state of the industry annual worldwide progress report, Fort Collins, Colorado, USA.

Yang, S. and Zhao, Y.F. (2015), "Additive manufacturing-enabled design theory and methodology: a critical review”, International Journal of Advanced Manufacturing Technology, Vol. 80 No. 1-4, pp. 327-342. https://doi.org/10.1007/s00170-015-6994-5

Yilmaz, S. and Seifert, C.M. (2011), "Creativity through design heuristics: A case study of expert product design", Design Studies, Vol. 32 No. 4, pp. 384-415.

Angelica Lindwall, PhD student

Luleå University of Technology, Department of Business Administration, Technology and Social Sciences

Luleå campus, 97187 Luleå, Sweden

Email: angelica.lindwall@1tu.se 